\title{
THE GREEN ATTITUDE, INTENTION DAN BEHAVIOR COMPARISON BETWEEN GOVERNMENT AND PRIVATE EMPLOYEE (THE GUIDELINESS)
}

\author{
Rizka Zulfikar ${ }^{1}$, Prihatini Ade Mayvita ${ }^{2}$ dan Purboyo 3 \\ 1,2,3 Prodi Manajemen, Fakultas Ekonomi, Universitas Islam Kalimantan MAAB Banjarmasin, \\ Jalan Adhyaksa No. 2 Banjarmasin, Propinsi Kalimantan Selatan, Indonesia \\ E-mail: rizkazulfikar@gmail.com
}

\begin{abstract}
This research is a qualitative-quantitative descriptive to examine the comparison the level of green attitude, attention and behavior between government employees and the private sector. This research was conducted in South Kalimantan province from October 2018 to June 2019 using sample as many as 334 respondents consisting of 163 government employees and 171 private employees. These sample were taken by purposive sampling technique and using a questionnaire as an instrument. The data analysis technique is done by using (1) Descriptive qualitative analysis to describe the distribution of respondents (2) Compare means analysis to see the green attitude level, attention and behavior of each type of work (3) KolmogrovSmirnov Test to see the differences between the level of green attitude, attention and behavior of government and private employees and (3) Stuctural Equation Model to obtain a models which can be used to explained relationships between green attitude, attention and behavior.
\end{abstract}

Keywords: Green Attitude, Green Intention, Green Behavior

\begin{abstract}
ABSTRAK
Penelitian ini merupakan penelitian deskriptif kualitatif-kuantitatif untuk mengkaji komparasi tingkat green attitude, attention dan behavior antara pegawai pemerintahan dan swasta. Penelitan ini dilaksanakan di propinsi Kalimantan Selatan pada bulan Oktober 2018 hingga bulan Juni 2019 dengan populasi dan sampel adalah pegawai pemerintah dan pegawai swasta sebanyak 334 responden yang terdiri dari 163 pegawai pemerintah dan 171 pegawai swasta. Pola penarikan sampel dilakukan dengan teknik purposive sampling dan menggunakan kuesioner sebagai instrumen penelitian. Teknik analisis data dilakukan dengan menggunakan (1) Analisis deskriptif kualitatif untuk mengggambarkan sebaran respoden (2) Uji perbandingan rata-rata untuk melihat tingkat green attitude, attention dan behavior masing-masing jenis pekerjaan, (3) Uji Kolmogrov-Smirnov untuk melihat perbedaan tingkat green attitude, attention dan behavior pegawai pemerintahan dan swasta, (3) Stuctural Equation Model untuk mendapatkan model yang dapat menjelaskan hubungan antara green attitude, attention dan behavior.
\end{abstract}

Kata kunci: Green Attitude, Green Intention, Green Behavior 


\section{REFERENCES}

Ahmad, S. N. B., \& Juhdi, N. 2010. Organic Food: A Study on Demographic Characteristics and Factors Influencing Purchase Intentions among Consumers in Klang Valley, Malaysia. International Journal of Business and Management, 5(2), 105-118. Doi : 10.5539/ ijbm.v5n2p105

Akerhusrt, G. 2012. Re-examining green purchase behaviour and the green consumer profile: new evidences. Management Decision Journal. 50 (5) : 972-988.Doi

10.1108/00251741211227726

Alodini, A.A 2008, Factors that influence customers to pay more for environmentally friendly products (going green) in Universiti Sains Malaysia. MBA thesis. Universiti Sains Malaysia.

Aryanti, T., Utami, R.D. dan Gunarsih. 2014. Pengaruh Pengetahuan, Kepedulian, dan Sikap pada Lingkungan terhadap Minat Pembelian Produk Hijau. Media Trend. 9 (2) : 151-161.

Awad, T.A. 2011. Environmental segmentation alternatives: buyers' profiles and implications. Journal of Islamic Marketing, Vol. 2 Iss 1 pp. 55 $\begin{array}{lll}73 & \text { Doi } \\ 10.1108 / 17590831111115240\end{array}$

Baker, J.P, dan Ozaki, R. 2008. Pro-environmental products: marketing influence on consumer purchase decision. Journal of Consumer Marketing. 25 (5) : 281293.

Doi

10.1108/07363760810890516

Chen, T. B. dan Chai, L. T. 2010. Attitude Towards The Environment And Green Products: Consumer Perspective. Management Science And Engineering

Vol. 4(2) : 27-39.

Deliana, Y. 2012. Market segmentation for organic products in Bandung West Java, Indonesia', Research Journal of Recent Sciences, vol. 1, hal. 48-56.

Do Paço, A.M.F dan Raposo, M.L.B. 2010. Green consumer market segmentation: empirical findings fromPortugal. International Journal of Consumer Studies: 34 (2010) 429-436 . doi: 10.1111/j.1470-6431.2010.00869.x

D'Souza, C., Taghian, M. dan Khosla, R. 2007. Examination Of Environmental Beliefs And Its Impact On The Influence of Price, Quality And Demographic Characteristics With Respect To Green Purchase Intention. Journal of Targeting, Measurement And Analysis For Marketing. Vol. 15(2) : 69-78. Doi : 10.1057/palgrave.jt.5750039

Dumanovsky, T. Huang, C.Y. Bassett, M.T. dan Silver. L. D. 2010. Consumer Awareness of Fast-Food Calorie 
Information in New York City After Implementation of a Menu Labeling Regulation. American Journal of Public Health. December. 100 (12) : 2520-2525.

DOI:10.2105/AJPH.2010.191908

Garnida, N., J.H. Tjakraatmadja, R.A. Nasution, dan M.S. Purwanegara, 2014, Restructuring Knowledge of Organic Customer Profile within KMCRM Framework, International Food Research Journal, 21 (3) : 855-862

Ghozali, I dan Fuad, 2011. Structural Equation Modeling : Teori, Konsep, dan Aplikasi dengan Program AMOS 21.Badan Penerbit - Undip. Semarang.

Girard, T. 2010. The Role of Demographics on The Susceptibility to Social Influence: A Pretest Study. Journal of Marketing Development and Competitiveness. 5(1) : 9 - 22.

Haden, S.S.P. 2009. Historical, practical, and theoretical perspectives on green management: an exploratory analysis. Management Decision. Vol. 47(7) : 1041-1055. Doi : 10.1108/00251740910978287

Hamzan, W. dan Bayu, R. 2012. Hubungan Variabel Demografi dengan Respon Konsumen Terhadap Iklan Merk Top Coffee di Kota Denpasar. Jurnal Ekonomi, 2(9) : 1036-1052.

Hamdani, D. 2015, 'The influence of green marketing and innovation on green purchase intention (Study on consumers' organics vegetables purchasing at Yogya Riau Junction
Department Store in Bandung), Proceeding of First International Conference on Economics and Banking : 5-10

Hartono, A. 2008. Adopting SocioDemographic Characteristics In Profiling Green Consumers: A Review Of Hypotheses . Jurnal Siasat Bisnis. $12(1): 55-62$.

Haryadi, R. 2009. Pengaruh Strategi Green Marketing terhadap Pilihan Konsumen Melalui Pendekatan Marketing Mix. Tesis. Magister Management Universitas Dipenogoro.

Huang, C. dan Kung, F. 2011. Environmental consciousness and intellectual capital management. Management Decision. 49 (9) : 140525.

Doi:10.1108/00251741111173916

Irawan, R \& Darmayanti, D. 2008. The influence factors of green purchasing behavior : A study of university students in Jakarta. Proceeding of 6th Asian Business Research Conference. $\therefore 1-11$

Jain, S.K. dan Kaur, G. 2006. Role of Sociodemographics in Segmenting and Profiling Green Consumers: An Exploratory Study of Consumers in India. Journal of International Consumer Marketing, 18 (3), 107142. Doi : /10.1300/J046v18n03_06

Jaolis F. 2011. Profil Green Consumers Indonesia: Identifikasi Segmen Dan Faktor-Faktor Yang Mempengaruhi Perilaku Pembelian Green Products. 
Jurnal Mitra Ekonomi dan Manajemen Bisnis 2(1): 18-39.

Junaedi, MFS. 2008. Pengaruh gender sebagai pemoderasi pengembangan model perilaku konsumen hijau di Indonesia. Kinerja. 12(1): 17-37.

Kasali, R. 2007. Membidik Pasar Indonesia Segmentasi Targeting Positioning. PT Gramedia Pustaka Utama. Jakarta.

Kim, S. dan Seock, Y. K. 2009. Impacts Of Health And Environmental Consciousness On Young Female Consumers' Attitude Towards And Purchase Of Natural Beauty Products. International Journal of Consumer Studies. 33(6) : 627-638. Doi : 10.1111/j.1470-6431.2009.00817.x

Koç, B. dan Ceylan, M. 2009. ConsumerAwareness and Information Sources on

Food Safety: A Case Study of Eastern Turkey. Nutrition \& Food Science. 39(6) : 643-654.

Kotler, P. dan Armstrong, G. 2012. Principles of Marketing. Edisi Keempat Belas. Pearson-Prentice Hall : New Jersey.

Lee, K.H. 2009. Why and how to adopt green management into business organizations? : The case study of Korean SMEs in manufacturing industry. Management Decision. 47 (7) : 1101-1121. Doi : 10.1108 100251740910978322

Mayvita, P. A., \& Zulfikar, R. (2018). ANALISIS POSITIONING RUMAH
MAKAN KHAS BANJAR

BERDASARKAN PERSEPSI KONSUMEN

(Studi Pada Warung Makan Fauzan, Warung Makan Mona dan Warung Makan Idah Jaya di Banjarmasin). Jurnal Ekonomi dan Manajemen, 19(1).

Mayvita, P. A., \& Zulfikar, R. (2019). THE LEVEL OF COGNITIVE, AFFECTIVE AND KONATIVE BANJARMASIN'S PUBLIC BASED ON DEMOGRAPHIC AND PSYCHOGRAFIC IN RESPONDING TO PROHIBITION POLICY THE USE OF PLASTIC AS SHOOPING BAGS. Jurnal Ekonomi dan Manajemen, 19(2), 637 649.

Miranti. S. 2012. Pengaruh Perbedaan Jenis Kelamin terhadap perilaku pembelian produk hijau di Jakarta. Tesis. Fakultas Ekonomi Progaram Studi Magister Manajemen. Universitas Indonesia.

Molina-Azorın, J., Claver-Corte's, E., Lo'pez-Gamero, M. dan Tarı, J. (2009), "Green management and financial performance: a literature review", Management Decision, Vol. 47 No. 7, : 1080-100. Doi : $10.1108 / 00251740910978313$

Mostafa, M. M. (2006). Antecedents of Egyptian Consumers' Green Purchase Intentions: A Hierarchical Multivariate Regression Model. Journal of International Consumer Marketing. 19 : 97- 126. Doi : 10.1300/J046v19n02_06

Muhmin, A. G. (2007). Explaining consumers' willingness to be environmentally 
friendly. International Journal of Consumer Studies, 31(3), 237-247. Doi $\quad: 10.1111 / \mathrm{j} .1470$ 6431.2006.00528.x

Muzayanah, F.N. Suroso. A. I. dan Najib, M 2015. Faktor-Faktor Yang Mempengaruhi Resistensi Pembelian Pangan Organik Dan Proses Pendidikan Konsumen. Jurnal Manajemen \& Agribisnis. 12 (3) : 163 $-173$.

Samin, R. Rahman, M. S. dan Javadian, J. 2013. Consumers Perceptual Differences in Buying Cosmetic Products : Malaysia Perspective. International Journal of Scientific Research, 16(11) : 345 - 355. DOI: 10.5829/idosi.mejsr.2013.16.11.1203 4

Schiffman, L.G. dan Kanuk, L.L. 2008. Perilaku Konsumen.. Edisi Ketujuh. PT. Indeks. Jakarta.

Soonthonsmai, V. 2007. Environmental Or Green Marketing As Global Competitive Edge:Concept, Synthesis, And Implication. EABR (Business) And ETLC (Teaching) Conferenceproceeding, Venice, Italy

Sudiyanti, 2009. Predicting women purchase intention for green food products in Indonesia. Master Thesis. University of WisconsinWhitewater. US

Suprapto, B. dan Wijaya, T. 2012. Intentions of Indonesian consumers on buying organic food. International Journal of Trade,
Economics and Finance, vol. 3, hal. 114-119

Syahbandi. 2012. Implementasi Green MarAnalisisketing Melalui Pendekatan Marketing MIX, Demografi dan Pengetahuan Terhadap Pilihan Konsumen (Studi The Body Shop Pontianak). Jurnal Ekonomi, Bisnis dan Kewirausahaan, $3(1)$.

Tsakiridou, E., Mattas, K. dan Bazoche, P., 2012. Consumers response on the labels of fresh fruits and related implications on pesticide use. Food Economics, 9(1-2) : 129-134.

Waskito, J. dan Harsono, M. 2011. Pengembangan dan Implementasi Model Strategi Pemasaran Berwawasan Lingkungan: Studi Empiris Pada Masyarakat Joglosemar. Jurnal Dinamika Manajemen. 3(1): 33-39.

Widodo, A., Rubiyanti, N. Dan Nandary, T. 2015. Factors influencing green purchasing behavior (Study on university student in Bandung)'. Full Paper Proceeding GTAR. 2 : 775-785

Widjojo, H. dan Yudianto, B.R. 2015. 'Factors considered by Indonesian youth in buying green product. Purushartha. $7: 13-26$.

Widyastuti, N.P.A. dan Widagda. K. I. 2012. Pengaruh Faktor Demografi Dan Lingkungan Sosial Terhadap Keputusan Pembelian Dimediasi Oleh Perilaku Membaca Atribut Label. Jurnal Ekonomi. 2(1): 1398-1411. 
Yahya. 2011. Pengaruh Variabel Demografi Konsumen Terhadap Keputusan Pembelian Produk. Jurnal Ekonomi. 8(1) : 23-40.

Yasa, B.M.A.S dan Ekawati, N.W. 2015. Peran Gender Dalam Menjelaskan Pengaruh Sikap Dan Norma Subyektif Terhadap Niat Beli (Studi Kasus Produk Kosmetik Hijau Merek Oriflame Di Kota Denpasar). E-Jurnal Manajemen Unud, 4 (7): 1785-1797.

Zulfikar, R., \& Mayvita, P. A. (2017, December). Tingkat Kepercayaan dan Minat Beli Masyarakat Banjarmasin Terhadap Produk Hijau Berdasarkan Segmentasi Demografis. In Proceeding of National Conference on Asbis (Vol. 2, No. 1, pp. 410-426).

Zulfikar, R., \& Mayvita, P. A. (2018). The Relationship of Perceived Value, Perceived Risk, and Level of Trust Towards Green Products of Fast Moving Consumer Goods Purchase Intention. JEMA: Jurnal Ilmiah Bidang Akuntansi dan Manajemen, 15(2), 85-97.

Zulfikar, R., \& Mayvita, P. A. (2019). Does Green Economy Video Really Work? The Effectiveness of Using Video Content Marketing in Forming MSMEs Perception and Behavior to Implement Green Economy. JEMA: Jurnal Ilmiah Bidang Akuntansi dan Manajemen, 16(1), 34-45.

Zulfikar, R., Mayvita, P. A., \& Purboyo, P. (2019). ADOPSI TEKNIK PENYUSUNAN BUSINESS PLAN MODEL CANVAS UNTUK PERENCANAAN BISNIS UMKM
KULINER JALANAN DI KAWASAN

GATOT

SUBROTO

BANJARMASIN. JURNAL

PENGABDIAN

AL-IKHLAS

UNIVERSITAS ISLAM KALIMANTAN

MUHAMMAD ARSYAD AL

$B A N J A R Y, 4(2)$.

Zulfikar, R., \& Banjarmasin, U. I. K. M. The Structural Equation Models Of Environmental Concern and Knowledge To Green Trust and Green Purchase Intention Towards Green Products (Guideliness). Osf.io

Zulfikar, R., \& Mayvita, P. A. (2019). DIVERSIFIKASI PRODUK OLAHAN BERBASIS IKAN PATIN SEBAGAI POTENSI USAHA BAGI PANTI ASUHAN AL AMIN DAN SULTAN SURIANSYAH BANJARMASIN. JURNAL PENGABDIAN AL-IKHLAS UNIVERSITAS ISLAM KALIMANTAN MUHAMMAD ARSYAD AL $B A N J A R Y, 4(1)$. 